\title{
Understanding Clumped Isotope Reordering Kinetics in Carbonate Minerals Using Ab-Initio Molecular Dynamics Simulations
}

\author{
WASIF ZAHEER, ETHAN GROSSMAN AND SARBAJIT \\ BANERJEE
}

Texas A\&M University

Presenting Author: wasif.zaheer@tamu.edu

Elucidating the atomistic basis for the calcite-to-dolomite transformation can provide insight into processes controlling clumped isotope reordering in carbonates, and enhance clumped isotope applications for delineation of basin thermal histories. We have sought to determine the thermodynamic phase stabilities and transformation pathways in the $\mathrm{Mg}-\mathrm{Ca}-\mathrm{CO}_{3}$ system. We have calculated formation energy values for stoichiometrically equivalent $\mathrm{Mg}_{x} \mathrm{Ca}_{l-x} \mathrm{CO}_{3}$ structures in calcite and dolomite phases as a function of $\mathrm{Mg}$ concentration to compare their thermodynamic stabilities using plane wave simulations. The fundamental origin of the barriers for calcite-todolomite phase transformation are the activation energy penalties associated with bond breaking. The calcite-dolomite transformation mechanism is of fundamental importance to understanding declumping of clumped isotopes wherein similar bond breaking needs to be invoked. In order to examine the pathways for calcite-to-dolomite transformations, ab initio molecular dynamics (AIMD) simulations have been performed. The rearrangement of $\mathrm{Mg}$ atoms requires breaking a host of $\mathrm{M}-\mathrm{O}$ bonds $(\mathrm{M}=\mathrm{Ca}, \mathrm{Mg})$ in $\mathrm{Mg}$-doped calcite. The free energy required to break these $\mathrm{M}-\mathrm{O}$ bonds far exceeds the enthalpic stability provided by the rearrangement of $\mathrm{Mg}$ atoms and the transformation of Mg-doped calcite into dolomite. Therefore, the transformation is kinetically strongly inhibited and cannot be observed through thermal annealing. AIMD simulations performed on a 270-atom supercell with the composition $\mathrm{Ca}_{27} \mathrm{Mg}_{27}\left(\mathrm{CO}_{3}\right)_{54}$ show off centering of atoms from their ground state positions upon simulated annealing to $900^{\circ} \mathrm{C}$. However, the rearrangement of $\mathrm{Mg}$-rich calcite into dolomite is not observed. These results suggest the operation of alternative low-energy pathways, perhaps involving disordered intermediate structures. Furthermore, first-principles calculations using the nudged elastic band formalism and ab initio molecular dynamics simulations have been performed to explore cation rearrangement and declumping mechanisms with a particular emphasis on the role of hydroxyl and bicarbonate species stabilized within the structures that possible serve as reaction intermediates. These calculations have shown how the presence of hydroxyl groups and formation of bicarbonates facilitates declumping in carbonate minerals. 